\title{
Telemedicine in chronic obstructive pulmonary disease: a possible transition to the patient independence
}

Florin Mihălțan*, Valentin Coșei, Corina Borcea, Ancuta Constantin

Abstract

Carol Davila University of Medicine and Pharmacy, Bucharest, Romania

English:

Telemedicine remains a challenge for many diseases. Chronic obstructive pulmonary disease is a common illness already benefitting from a multitude of interventions in this area. They are discussed by the authors from the point of view of the benefits and limitations of telemedicine's involvement in the diagnosis and therapy of this chronic obstructive disease.

Keywords

telemedicine $\cdot \mathrm{COPD} \cdot$ exacerbation

\section{Telemedicina în bronhopneumopatia cronică obstructivă (bpoc) - o posibilă tranziție spre independența pacientului}

Rezumat

\begin{abstract}
Romanian:
Telemedicina rămâne pentru multe afecțiuni o provocare. BPOC, o boală frecventă, beneficiază deja de o multitudine de intervenții în acest domeniu. Ele sunt discutate de autori atât din punctul de vedere al beneficiilor cât și ale limitelor implicării telemedicinii în diagnosticul și terapia acestei afecțiuni cronice obstructive point.
\end{abstract}

Cuvinte-cheie

telemedicină $\bullet B P O C \cdot$ exacerbare

Respiratory patients are the ones with many home adapting problems. In many statistics, the rehospitalisation in the next 30 days after discharged of this sample of suffering persons is frequent; 1 of 4 or 5 patients with chronic obstructive diseases, congestive cardiac failure or diabetes mellitus are coming back (1). There are many solutions to help these patients. One of them is telehealth. Telemedicine assures the distribution of services, by healthcare distributors and providers (without any problem of distance), using information and communication technologies and helping the patients with exchanging information on diagnosis and treatment (2). Telemonitoring is only one of the offers consisting of digital/satellite/wireless/ broadband or Bluetooth transmission of many non-invasive data (a major part of them from the physiological status of the patient).

Chronic obstructive pulmonary disease (COPD) is one of the chronic respiratory diseases with many connective problems induced by long-life surviving of these patients, polimorbidity,

*Corresponding author: Florin Mihălțan, "Marius Nasta" Institute of Pneumophtysiology, Sos. Viilor 90, Sector 5, Bucharest, Romania.

E-mail:mihaltan@starnets.ro 
exacerbation rate and prolonged hospitalisations. If we look at self-management interventions using written action plans, communication with healthcare professionals brings some benefits concerning health status and lower probability of both respiratory-related and all-cause hospitalisation $(3,4)$. The main problems for transition at home of these patients are heterogeneity and multidimensional of diseases and interventions, comorbidities and level of education of practitioners in charge for every patient. For an easy life of health practitioners, it seems that the rapid development of technologies and information can be an important weapon for earlier detection of exacerbations and earlier therapeutically intervention.

\section{Results of different studies concerning telemonitoring}

There are many offers for monitoring of the COPD patients at home. In one study Promete II, the authors tried to compare a specific telemedicine system with routine clinical practice in cases of severe COPD (5). They used for telemonitoring equipment for blood pressure, heart rate, oxygen saturation and spirometry measurements (actively or passively collected by the patients). It was not a success because, in comparison with routine practice, this telemonitoring did not reduce the admission to the emergency department and hospitalisations. It demonstrates that having only telehealth physiological monitoring of severe COPD, for a long term, will unlikely be of benefit, and focused more on the limits of telemedicine. At the opposite Promete I, after 7-month of monitoring of elderly, severe COPD patients, and follow-up showed a significant reduction of hospitalisation, a period of stay on mechanical ventilation and visits to the emergency department, confirming the practicality of telehealth assistance for these severe COPD patients (6). Also, in other meta-analyses, there are conflicting results. The Cochrane review of 10 randomised controlled trials showed different results; some of them also confirm the absence of significantly improving the quality of life by using telehealth but with some benefits related to significantly reducing the risk of emergency department attendance and hospitalisation (7). On the other hand, a more recent meta-analysis of 18 trials found no statistically significant quality-of-life benefits (8). What are the limits of every evaluation of these studies? If we look at the parameters used for monitoring the first question is: are they appropriate? Blood pressure, O2 saturation and respiratory rate are usually reflecting severe exacerbations but not an early moment of an exacerbation (3). It is difficult for the practitioner and patient to be alerted in time and to prevent further complications of the disease. Another problem of telemonitoring particularly in COPD is the substantial variability of different telemonitoring interventions and applications used. We have a variety of tools for monitoring starting with:

1. traditionally recording and electronic transmission of physiological parameters and vital signs (spirometry, pulse oximetry, heart rate, breathing frequency and blood pressure);

2. technology platforms for delivery of education and transmission of pedometer results; hand-held monitors, self-reported symptoms and manually entered body temperature and oximetry;

3. sensor-containing wristbands for heart rate, physical activity, near body temperature and galvanic skin response;

4. commercial oximeters and cell phones coupled with a wristband;

5. self-reported data transmitted through cell phones (the EXACT-PRO (exacerbations of chronic pulmonary disease tool patient-oriented outcome) questionnaire);

6. and automated alert calls based on winter weather conditions $(9,10)$. Comparing the results using different tools is difficult. This can be another explanation of conflicting results. One study with negative results is the Chromed Trial (10). The authors evaluated the efficacy of home monitoring of lung mechanics by the forced oscillation technique and cardiac parameters in older patients with COPD and comorbidities. They found no change, using remote monitoring of lung function by forced oscillation technique and cardiac parameters, in time to first hospitalisation and in Euro QoL EQ-5D utility index score (a five-item descriptive system that measures five dimensions of health status mobility, self-care, usual activities, pain/discomfort and anxiety/depression) with three levels per dimension (no problem, some problems and extreme problems).Some other authors using only oxygen saturation telemonitoring reported that a decrease of more than $4 \%$ can be, in a day-to-day evaluation, an alarming event, predicting an exacerbation of COPD (11). There is another type of evaluation on meta-ethnography of the experience of patients (12) with telemedicine care. It seems that patients with more severe diseases are likely to benefit the most. But all this depends on the modality of involving the emotional and social of the patient and on the clinical support (with regular contact with the health care provider and professionals meeting the requirements of the patients) (12). Helping the self-management of patients by giving patients large access to COPD web (13) is another possible way using new digital technology. A possible solution is telemonitoring in severe COPD cases (comprising a recording of symptoms, oxygen saturation, spirometry and video consultations) (14). The authors found the improvement of quality of life (health- 
related questionnaire $\left(15 \mathrm{D}^{\odot}\right)$ but without any impact on the CAT scale. For elderly advanced COPD or chronic heart failure patients, the telemonitoring supported by hospitalbased home care (15), consisting of a health diary system, based on a digital pen technology, can significantly reduce the hospitalisations.

\section{Other opportunities provided by digital technologies in COPD}

Another open window for COPD, coming from telehealth medicine is telerehabilitation (TR) (16). There are, of course, also some barriers from the staff' perspective such as: 1) skills, 2) professional role and identity, 3) beliefs about capabilities, 4 ) beliefs about consequences, 5) environmental context and resources and 6) social influences. At the same time, there are two key messages for assuring the TR success: a combination between the involvement of the health professionals in the decision process with sufficient education and skill training of patients and responsible for delivering the messages. One possibility is digitalising pulmonary rehabilitation (PR) with a smartphone app. This is feasible and accepted by selected patients included in a 20-day core programme with short-term improvements of health-related quality of life (17). It also seems that the problem of safety, feasibility and effectiveness of this virtual TR is solved (18). It is another study that demonstrates that live video conferencing with a hub where 24 patients were receiving 14 sessions of standard, outpatient, multi-disciplinary PR in a hospital is improving shuttle walk test with less staffing ratios and significantly less travelling. Introduction of mHealth (personal digital assistants and monitoring) and eHealth (delivery, surveillance and management through telehealth communication) is working for elderly people but with two conditions (19): they must be guided to ensure valid and reliable online sources and to create the ability to interact with peers who had similar experiences. For therapy, telemonitoring is useful. Video telehealth inhaler training sessions using teach to goal methodology is another occasion to use telemedicine for improving patient acceptance of inhaling techniques in rural areas (20). Benefits for therapy are also evident. Enrolling patients with COPD in a digital platform to help to manage their medications and symptoms (21), receiving electronic medications monitor (and a smartphone app to track use trends and feedback), to monitor short-acting beta 2 agonists (SABA), brings a reduction of SABA use and more SABA free days.

Concerning cost evaluation, if we are looking to Chromed study (10), applying the prespecified health economic analysis the authors suggest it is possible to have a $27 \%$ reduction in the healthcare costs in the intervention (per patient per year, largely driven by a reduction in hospital costs). Even so in our days, the economic benefit of telemonitoring in COPD remains unclear (22), reflecting the difficulty in isolating the effects of telemonitoring from educational interventions (23). One condition for telemonitoring to be truly cost-effective is to have an annual cost of equipment and technical support at a price less than the annualised difference in costs between intervention and control groups

If we look at the conclusions of experts in 2019 (24), there are no differences in comparison with the round tables organised in 2018 (25). There is still much conflicting information regarding the effectiveness of telemonitoring for COPD patients with an overall improvement in more than $45 \%$ of the articles but also with the absence of this improvement in 38\% (24). They defined some barriers such as low-quality data, costs, increase the workload for providers and as benefits, they underline these aspects: less in-person visits, better disease management and a better relationship-patient-provider-health assistant. Concerning patients' opinions, these sometimes are similar to them of the healthcare providers. If we look at future mHealth interventions for patients and healthcare providers, they should focus (26) on developing self-management skills over time by providing adequate information, decision support and feedback on self-management behaviour. At the same time, mHealth should complement regular care (26).

\section{Recommendations for future implementing of telehealth actions}

The best telemonitoring outcomes for the future come from programmes dedicated to a certain cluster of patients with COPD (comprising aged and very sick patients, frequent exacerbators with multimorbidity and limited community support). There are also some important conditions for users. Programmes must use third-generation telemonitoring, flexible, adapted (to our diverse healthcare contexts) systems providing constant analytical and decision-making support (24 h/day, 7 days/week). We have to identify correctly who are the ideal candidates, at what time they need it and for how long (10). It seems that even for starting at home noninvasive ventilation in hypercapnic COPD patients, the use of telemedicine is noninferior to in-hospital initiation and brings over $50 \%$ of cost reduction (27). The extension of telehealth in community services is already a certainty. One example is England and Wales where one-third of the respondents are already using telehealth (28).

\section{Conclusions}

Despite the expansion of telemedicine in COPD, the science behind telemedicine in COPD remains underdeveloped (25). 
That is why it is a strong need to develop the necessary and definitive scientific basis for clarifying the role of telemedicine in the medical management of our patients.

\section{References}

1. Arcilla D, Levin D, Sperber M. Transitioning patients to independence. Home Healthcare Now. 2019;37(3): 159-164.

2. Ambrosino $\mathrm{N}$, Vagheggini $\mathrm{G}$, Mazzoleni $\mathrm{S}$, Vitacca $M$. Telemedicine in chronic obstructive pulmonary disease. Breathe (Sheff). 2016;12(4): 350-356.

3. Bourbeau J, Farias R. Making sense of telemedicine in the management of COPD. European Respiratory Journal. 2018;51(5): pii:1800851.

4. Lenferink A, Brusse-Keizer M, van der Valk PD, Frith PA, Zwerink $M$, Monninkhof EM, et al. Self management interventions including action plans for exacerbations versus usual care in patients with chronic obstructive pulmonary disease. Cochrane Database of Systematic Reviews. 2017;8: CD011682.

5. Ancochea J, García-Río F, Vázquez-Espinosa E, HernandoSanz A, López-Yepes L, Galera-Martínez R, et al. Efficacy and costs of telehealth for the management of COPD: the PROMETE II trial. European Respiratory Journal. 2018;51(5): pii:1800354.

6. Segrelles Calvo G, Gómez-Suárez C, Soriano JB, Zamora E, Gónzalez-Gamarra A, González-Béjar M, et al. A home telehealth program for patients with severe COPD: the PROMETE study. Respiratory Medicine. 2014;108(3): 453-462.

7. McLean S, Nurmatov U, Liu JL, Pagliari C, Car J, Sheikh A. Telehealthcare for chronic obstructive pulmonary disease: Cochrane Review and meta-analysis. British Journal of General Practice. 2012;62: e739-e749.

8. Gregersen TL, Green A, Frausing E, Ringbæk T, Brøndum E, Suppli Ulrik C. Do telemedical interventions improve quality of life in patients with COPD? A systematic review. International Journal of Chronic Obstructive Pulmonary Disease. 2016;11: 809-822.

9. Vitacca M, Montini A, Comini L. How will telemedicine change clinical practice in chronic obstructive pulmonary disease? Therapeutic Advances in Respiratory Disease. 2018;12: 1753465818754778.

10. Walker PP, Pompilio PP, Zanaboni P, Bergmo TS, Prikk K, Malinovschi A, et al. Telemonitoring in COPD: the CHROMED study, a randomized clinical trial. American Journal of Respiratory and Critical Care Medicine. 2018;198(5): 620-628.

11. Dymanowska JM, Białas AJ, Górski P, Piotrowski WJ. The evaluation of home oxygen saturation for prediction of acute exacerbations of COPD. European Respiratory Journal. 2017;50 (Suppl. 61): PA1101.

12. Barken TL, Söderhamn U, Thygesen E. A sense of belonging: a meta-ethnography of the experience of patients with chron- ic obstructive pulmonary disease receiving care through telemedicine. Journal of Advanced Nursing. 2019;75(12): 3219-3230.

13. Stenlund T, Nyberg A, Lundell S, Wadell K. Web-based support for selfmanagement strategies versus usual care for people with COPD in primary healthcare: a protocol for a randomised, 12-month, parallel-group pragmatic trial. BMJ Open. 2019;9(10): e030788.

14. Tupper OD, Gregersen TL, Ringbaek T, Brøndum E, Frausing E, Green A, et al. Effect of tele-health care on quality of life in patients with severe COPD: a randomized clinical trial. International Journal of Chronic Obstructive Pulmonary Disease. 2018;13: 2657-2662.

15. Persson $\mathrm{HL}$, Lyth J, Wiréhn $A B$, Lind L. Elderly patients with COPD require more health care than elderly heart failure patients do in a hospital-based home care setting. International Journal of Chronic Obstructive Pulmonary Disease. 2019;14: 1569-1581.

16. Damhus CS, Emme C, Hansen H. Barriers and enablers of COPD telerehabilitation - a frontline staff perspective. International Journal of Chronic Obstructive Pulmonary Disease. 2018;13: 2473-2482.

17. Rassouli F, Boutellier D, Duss J, Huber S, Brutsche MH. Digitalizing multidisciplinary pulmonary rehabilitation in COPD with a smartphone application: an international observational pilot study. International Journal of Chronic Obstructive Pulmonary Disease. 2018;13: 3831-3836.

18. Knox L, Dunning M, Davies CA, Mills-Bennet R, Sion TW, Phipps $\mathrm{K}$, et al. Safety, feasibility, and effectiveness of virtual pulmonary rehabilitation in the real world. International Journal of Chronic Obstructive Pulmonary Disease. 2019;14: 775-780.

19. Disler RT, Inglis SC, Newton P, Currow DC, Macdonald PS, Glanville AR, et al. Older patients' perspectives of online health approaches in chronic obstructive pulmonary disease. Telemedicine Journal and e-Health. 2019;25(9): 840-846.

20. Locke ER, Thomas RM, Woo DM, Nguyen EHK, Tamanaha BK, Press VG, et al. Using video telehealth to facilitate inhaler training in rural patients with obstructive lung disease. Telemedicine Journal and e-Health. 2019;25(3): 230-236.

21. Chen J, Kaye L, Tuffli M, Barrett MA, Jones-Ford S, Shenouda $\mathrm{T}$, et al. Passive monitoring of short-acting beta-agonist use via digital platform in patients with chronic obstructive pulmonary disease: quality improvement retrospective analysis. JMIR Formative Research. 2019;3(4): e13286.

22. Goldstein RS, O'Hoski S. Telemedicine in COPD: time to pause. Chest. 2014;145: 945-949.

23. Bolton CE, Waters CS, Peirce S, Elwyn G; EPSRC and MRC Grand Challenge Team. Insufficient evidence of benefit: a systematic review of home telemonitoring for COPD. Journal of Evaluation in Clinical Practice. 2011;17: 1216-1222.

24. Kruse $\mathrm{C}$, Pesek B, Anderson M, Brennan K, Comfort $\mathrm{H}$. Telemonitoring to manage chronic obstructive pulmonary 
disease: systematic literature review. JMIR Medical Informatics. 2019;7(1): e11496.

25. Donner CF, Raskin J, ZuWallack R, Nici L, Ambrosino N, Balbi $B$, et al. Incorporating telemedicine into the integrated care of the COPD patient a summary of an interdisciplinary workshop held in Stresa, Italy, 7-8 September 2017. Respiratory Medicine. 2018;143: 91-102.

26. Korpershoek YJG, Vervoort SCJM, Trappenburg JCA, Schuurmans MJ. Perceptions of patients with chronic obstructive pulmonary disease and their health care providers towards using mHealth for self-management of exacerbations: a qualitative study. BMC Health Services Research. 2018;18(1): 757.

27. Duiverman ML, Vonk JM, Bladder G, van Melle JP, Nieuwenhuis $J$, Hazenberg A, et al. Home initiation of chronic non-invasive ventilation in COPD patients with chronic hypercapnic respiratory failure: a randomised controlled trial. Thorax. 2020;75: 244-252.

28. Alrajeh AM, Aldabayan YS, Aldhair AM, Pickett E, Quaderi SA, Alqahtani JS, et al. Global use, utility, and methods of tele-health in COPD: a health care provider survey. International Journal of Chronic Obstructive Pulmonary Disease. 2019;14: 1713-1719. 